Journal of

Dentistry and Oral Health

\title{
Intracanal Antimicrobial against Enterococcus Faecalis
}

\author{
Flavia FZ Oliveira ${ }^{1}$, Viviane AA Rodrigues ${ }^{2}$, Ana PF Nunes ${ }^{1}$, Karla MR Alcântara ${ }^{1}$, Rosana S Pereira ${ }^{1}$, \\ Mario J Avila-Campos ${ }^{2, *}$
}

${ }^{1}$ Department of Dental Clinical and Pathology, Federal University of Espirito Santo, Vitoria, ES, Brazil

${ }^{2}$ Anaerobe Laboratory, Department of Microbiology, Institute of Biomedical Science, University of São Paulo, Sao Paulo, SP, Brazil

${ }^{\star}$ Corresponding author: Mario J. Avila-Campos, Av. Professor Lineu Prestes 1374, 05508-900, Sao Paulo, SP, Brazil; Tel: +55-11-30917344; E-mail: mariojac@usp.br

Received Date: April 28 2016; Accepted Date: July 06 2016; Published Date: August 042016

Citation: Flavia FZ Oliveira, et al. (2016) Intracanal Antimicrobial against Enterococcus Faecalis. J Dent Oral Health 2: 1-5

\begin{abstract}
Aims: The efficacy of sodium hypochlorite associated with either chlorhexidine or calcium hydroxide, in reducing E. faecalis counts was evaluated by an in vitro infection-induced model.

Materials and Methods: Thirty-four root-canal-treated human molar teeth were infected with E. faecalis for 14 days. After this period, 13 teeth were treated with chlorhexidine; 13 teeth with calcium hydroxide; and, eight teeth with saline. The teeth were sampled immediately after chemo-mechanical preparation, 14 days after intracanal medication, and 7 days without any intracanal antimicrobial.
\end{abstract}

Results: A significant reduction of the number of E. faecalis within the root canal was observed with hypochlorite sodium plus calcium hydroxide or chlorhexidine, after 14 days of use.

Conclusions: These antimicrobial associations can be use during endodontic treatment.

Keywords: Endodontic infection; Enterococcus faecalis; Sodium hypochlorite; Chlorhexidine; calcium hydroxide

\section{Introduction}

The goals of endodontic therapy are to establish and maintain an aseptic condition inside the root canals and to treat periradicular diseases. The success rate for this therapy ranges between $53 \%$ and $95 \%$, which is probably due to differences in treatment modalities such as post-endodontic treatment follow up and diagnostic criteria [1,2]. Endodontic retreatment is still commonly performed by dentists in Brazil.

Endodontic instruments and chemical agents are necessary for cleaning and shaping the root canal [3]. Sodium hypochlorite $(\mathrm{NaOCl})$ is commonly used as an irrigating solution in endodontic procedures due to its antimicrobial action [4,5], and a combination of $\mathrm{NaOCl}$ with calcium hydroxide and/or chlorhexidine shows excellent disinfection when applied to the root canal $[6,7]$.

The microbial contamination plays a major role in the periapical etiopathogenesis. Many microorganisms that are resist-

C2013 The Authors. Published by the JScholar under the terms of the Creative Commons Attribution License http://creativecommons.org/licenses/ by/3.0/, which permits unrestricted use, provided the original author and source are credited. ant to multiple antimicrobials can infect the dentinal tubules and persist in the apical portion of the root canal; thus endodontic treatment is used to reduce the microbial load in these tissues. Studies using culture have demonstrated the presence of anaerobic bacteria in endodontic infections including the pulp cavities and periradicular abscesses $[8,9]$.

Enterococcus faecalis is often found in a canal with a necrotic pulp and during persistent or secondary endodontic infections, and this persistence in treated root-canals reflects its substantial resistance to hostile environments and nutritional scarcity [6].

The complex anatomy of the root canal, with the isthmus and the deltas, facilitates the persistence of this pathogen in the deeper areas that are beyond the reach of endodontic instruments and/or irrigating solutions; this explains the limited effectiveness of antimicrobial solutions in reducing or eliminating pathogens such as E. faecalis into root canal system [10].

Thus, the purpose of this study was to evaluate the effectiveness of specific antimicrobials in association against Enterococcus faecalis in an in vitro model of root-canal-treated teeth. 


\section{Materials and Methods}

This study was approved by the Ethics Committee of the Federal University of Espirito Santo (Process No. 290/10).

\section{Teeth selection}

Thirty-four molar teeth with three canals and completely formed apices were selected. Teeth having between 14 and $16 \mathrm{~mm}$ of root length, as measured from the cervical margin (cement-enamel junction) to the apex, were used; and teeth displaying calcifications, root resorption or a fourth canal were excluded of this study. All teeth were first submerged in $0.5 \%$ $\mathrm{NaOCl}$ for 12 hours to achieve surface disinfection and then kept in $0.85 \%$ phosphate buffered saline (PBS) until further use. Caries were removed using a digger's dentin with spherical steel bits (Duflex, SS-White, Rio de Janeiro, RJ, Brazil). Conventional cavities were performed using a spherical diamond bur (KG Sorensen Ind Com Ltd, Rio de Janeiro, RJ, Brazil) and a Endo Z drills (Dentsply; Maillefer-Ballaigues, Switzerland). The crowns were removed close to the cement-enamel junction using a diamond disk (No. 7020; KG Sorensen Ind Com Ltd, Rio de Janeiro, RJ, Brazil).

A dental K-file \#10 (Dentsply) was inserted into each canal using a magnifying glass, and its progress from the tip and through the apical foramen was carefully monitored. The working length was restricted to $1 \mathrm{~mm}$ less than the length of the file at the point where it exited the root. Canals were subsequently cleaned and shaped with K-files \#10 and \#15 to the last $1 \mathrm{~mm}$ of their working length. Canals were then irrigated with a solution containing $0.85 \%$ PBS and $17 \%$ EDTA (Biodynamic Products, Sao Paulo, SP, Brazil) to remove the smear layer. The teeth were placed into tubes containing $10 \mathrm{~mL}$ of trypticase soy broth (TSB) (Himedia Laboratories, Mumbai, India), subjected to ultrasonic agitation for $1 \mathrm{~min}$ to facilitate TSB penetration, removed and sterilized at $121^{\circ} \mathrm{C}$ for $20 \mathrm{~min}$. Adequate dental sterility was confirmed by incubation in TSB at $37^{\circ} \mathrm{C}$ overnight.

\section{Teeth Infection}

$1 \mathrm{~mL}$ of a 24 hour-culture of E. faecalis ATCC 29212 was used to inoculate $200 \mathrm{~mL}$ of TSB. The teeth were immersed in the inoculated TSB and kept for a maximum of 14 days with gentle shaking $\left(60 \mathrm{rpm}, 37^{\circ} \mathrm{C}\right)$ [11]. After 7 days of incubation, the broth medium was renewed as above. After 14 days of experimental contamination, 34 teeth were used for experiments and two additional teeth were analyzed by scanning electron microscopy (SEM, JEOL, Akishima, Japan).

\section{Experimental setup}

Twenty-six teeth were subjected to chemo-mechanical processes on a rotary nickel-titanium system (ProTaper Universal, Dentsply) according to the operative sequence recommended by the manufacturer. The canals were irrigated five times, during $30 \mathrm{~s}$ each time, with $1 \mathrm{~mL}$ of $5.25 \% \mathrm{NaOCl}$ (Pharmic pharmaceutical, Vitoria, ES, Brazil) using a $5 \mathrm{~mL}$ syringe with a 30-gauge needle, while the eight teeth of the control group were irrigated five-times with $0.85 \%$ PBS.

\section{Intracanal antimicrobials}

All the 26 teeth were randomly grouped. Group 1, 13 teeth filled with $2 \%$ chlorhexidine gel (Pharmic pharmaceutical, Vitoria, ES, Brazil); group 2, 13 teeth filled with glycerinate calcium hydroxide paste $\left(\mathrm{Ca}(\mathrm{OH})_{2}\right)$ (Pharmic pharmaceutical, Vitoria, ES, Brazil); and group 3, eight teeth filled with $0.85 \%$ PBS (control group). All canals were dried with paper points prior to being filled with the appropriate medication. A drill lentulo (spiral drill \#35, Dentsply) at low rotation speed was used to place the antimicrobial inside each canal. Subsequently, a needle tip was used to complete canal filling with $2 \%$ chlorhexidine gel, while $\mathrm{Ca}(\mathrm{OH})_{2}$ was applied with an endodontic syringe ML (Duflex-SSWhite). The canals were then sealed using a sterile cotton ball. Treated teeth were maintained in a tube with $50 \mathrm{~mL}$ of TSB at $37^{\circ} \mathrm{C}$ until the end of the experiment.

\section{Sample collection}

Samples from each root canal were taken, as follows: after bacterial contamination (S1); immediately after chemo-mechanical preparation (S2); after 14 days of intracanal antimicrobial (S3); and after seven days without any intracanal antimicrobial (S4). S1 samples were taken after 14 days of contamination, and each apex was sealed with cyanoacrylate cement (Superbonder, Henkel Loctite, Belo Horizonte, MG, Brazil) after sampling. For sampling, canals were filled with sterile $0.85 \%$ saline solution and samples were obtained with three paper points (Meta Biomed Co, Ltd) kept in place for $1 \mathrm{~min}$. The paper points were then transferred to a tube containing $1 \mathrm{~mL}$ of $0.85 \%$ PBS, vortexed twice, and for $30 \mathrm{~s}$ each time. Finally, the points were discarded and serial dilutions were performed. S2 samples were obtained immediately after instrumentation, and canals were filled with a $10 \%$ sodium thiosulfate solution before sample collection to inactive the $\mathrm{NaOCl}$ used previously. Canals were rinsed three times with PBS and a Hedstrom \#35 was used to soak the dentin walls for $1 \mathrm{~min}$.Teeth filled with chlorhexidine or $\mathrm{Ca}(\mathrm{OH})_{2}$ were sealed for 14 days, after which the seals and antimicrobials were removed, and the S3 samples were collected. Teeth without any medication were placed in a sterile dry tube for seven days, after which S4 samples were collected. These samples were evaluated for the presence of any residual bacteria.

\section{Experimental device setup}

After samples collection, each tooth was inserted individually into tapering Eppendorf plastic tubes (Eppendorf-Elkay, Shrewsbury, MA, USA). Each tooth was attached to the inside of the tube with the crown enclosed and the root protruding through the end. The teeth were sealed at the cement-enamel junction with cyanoacrylate to prevent external contamination. This set up, was then filled with $10 \mathrm{~mL}$ of TSB solution to ensure complete immersion of the dental root [12].

\section{Microbiological assessment}

After 14 days of dental exposure with E. faecalis, gram stain and biochemical assays were performed to prove the purity of strain. Bacterial quantification was performed on all teeth using serial dilutions (10-1 to 10-6), which were then plated $(0.1 \mathrm{~mL})$ onto blood agar and incubated at $37^{\circ} \mathrm{C}$ for 48 hours. Colonies were manually counted after the incubation period 
and $\mathrm{CFU} / \mathrm{mL}$ determined.

\section{Scanning electron microscopy}

Two teeth were analyzed by SEM to confirm the bacterial colonization. The roots were grooved at the long axis using a diamond blade No. 7020 (KG Sorensen Ind Com Ltd) and broken off with orthodontic pliers. The four hemi-parts were washed with PBS to remove excess TSB, fixed in $25 \%$ glutaraldehyde and $0.1 \mathrm{M}$ cacodylate buffer, kept at room temperature for 2 hours, washed twice with $0.1 \mathrm{M}$ cacodylate buffer $(\mathrm{pH} 7.2)$ for $10 \mathrm{~min}$, and finally fixed with $1 \%$ osmium tetroxide $\left(\mathrm{OsO}_{4}\right)$ in $0.1 \mathrm{M}$ cacodylate buffer containing $1.25 \%$ potassium ferrocyanide. The teeth were washed twice with ultrapure water (MilliQ) for $10 \mathrm{~min}$ and dehydrated using an ascending series of ethanol concentration $(30 \%, 50 \%, 70 \%, 90 \%$ and $100 \%)$ with a $10 \mathrm{~min}$ incubation period at each concentration. Teeth were desiccated using a critical point method appliance (Balzers CPD-030, Electron Microscopy Sciences, USA) on aluminum holders and covered with gold sputter (Balzers SCD-050, Electron Microscopy Sciences, USA). The samples were examined and photographed on a SEM JEOL 6100.

\section{Statistical analyses}

The Mann-Whitney test was used to compare differences between the experimental and control groups in the S2 samples. The Kruskal-Wallis test was used to compare values between the PBS, chlorhexidine and $\mathrm{Ca}(\mathrm{OH})_{2}$ groups in the $\mathrm{S} 3$ samples. The Tukey's test was used to detect differences between the chlorhexidine and $\mathrm{Ca}(\mathrm{OH})_{2}$ groups in the $\mathrm{S} 3$ samples.

\section{Results}

All teeth (S1 samples) showed similar levels of bacterial contamination after 14 days of exposure to E. faecalis with no significant difference of colonization. All teeth, irrespective of being treated with chlorhexidine, $\mathrm{Ca}(\mathrm{OH})_{2}$, or TSB (control), harbored E. faecalis and SEM revealed biofilm formation in the dentinal tubules after 14 days of infection with E. faecalis (Figure 1). After chemo-mechanical preparation of teeth from control group, a reduction of the microbial load was observed. Further, only 6 out of the 26 teeth showed bacterial growth in TSB after this preparation.

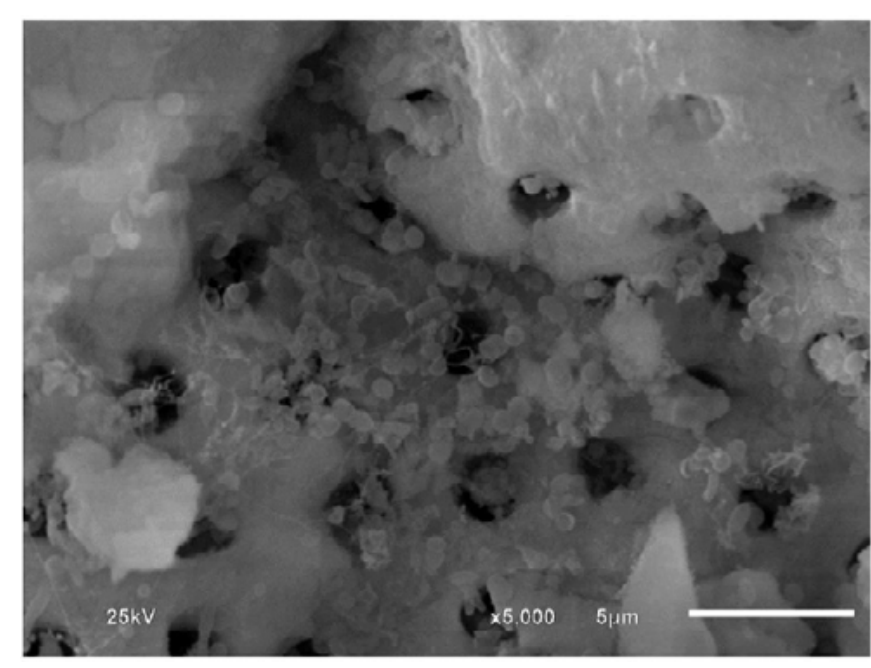

Figure 1: Electromicrograph of biofilm-forming Enterococcus faecalis in dentinal tubules after 14 days of infection.

In all groups with antimicrobials or PBS, no statistically significant values were observed $(\mathrm{P}<0.05)$ (Table 1$)$. However, $\mathrm{Ca}$ $(\mathrm{OH})_{2}$ was significantly more effective than PBS in reducing E. faecalis colony counts $(\mathrm{P}<0.001)$. Teeth treated with chlorhexidine (samples S3) for 14 days showed no bacterial growth while 5 out of the 13 treated teeth with $\mathrm{Ca}(\mathrm{OH})_{2}$ showed bacterial growth. At seven days, in the teeth without any intracanal antimicrobials, a low residual activity was observed, since E. faecalis grown in $63 \%$ of the teeth treated with $\mathrm{Ca}(\mathrm{OH})_{2}$ and in $78 \%$ of the chlorhexidine treated teeth; but, this difference was not statistically significant $(\mathrm{P}=0.2723)$.

\section{Discussion}

Enterococcus faecalis is a common persistent pathogen in endodontic infections; however, its role in primary and secondary infections is not well defined $[13,14]$. Studies have shown that $E$. faecalis is present in teeth showing root canal treatment failure and that it is highly resistant to endodontic treatment $[10,15]$. In this study, the efficacy of a combination of $\mathrm{NaOCl}$ and chlorhexidine or $\mathrm{Ca}(\mathrm{OH})_{2}$ in reducing E. faecalis from root canal-treated molar teeth was evaluated in vitro.

The culture method is the gold standard for bacterial isola-

\begin{tabular}{|c|c|c|c|c|c|c|}
\hline \multicolumn{2}{|c|}{ Antimicrobial groups } & \multirow[t]{2}{*}{$\begin{array}{l}\text { Difference among means } \\
\text { (I and II) }\end{array}$} & \multirow[t]{2}{*}{ Standard Deviation } & \multirow[t]{2}{*}{ P-value } & \multicolumn{2}{|c|}{ Limits of confidence interval $95 \%$} \\
\hline I & II & & & & Lower & Upper \\
\hline \multirow{3}{*}{ chlorhexidine } & chlorhexidine & --- & --- & --- & -- & -- \\
\hline & $\mathrm{Ca}(\mathrm{OH}) 2$ & -1.312 & 0.634 & 0.113 & -2.874 & 0.249 \\
\hline & PBS & $-5.576^{*}$ & 0.727 & 0 & -7.365 & -3.787 \\
\hline \multirow{3}{*}{$\mathrm{Ca}(\mathrm{OH}) 2$} & chlorhexidine & 1.312 & 0.634 & 0.113 & -0.249 & 2.874 \\
\hline & $\mathrm{Ca}(\mathrm{OH}) 2$ & --- & --- & --- & --- & --- \\
\hline & PBS & $-4.263^{*}$ & 0.727 & 0 & -6.052 & -2.474 \\
\hline \multirow{3}{*}{ PBS } & chlorhexidine & $5.576^{\star}$ & 0.727 & 0 & 3.787 & 7. 658 \\
\hline & $\mathrm{Ca}(\mathrm{OH}) 2$ & $4.263^{\star}$ & 0.727 & 0.000 & 2.740 & 6.052 \\
\hline & PBS & --- & --- & --- & --- & --- \\
\hline
\end{tabular}

Table 1: Antimicrobial efficacy between chlorhexidine, calcium hydroxide, and PBS groups, at S3 samples

${ }^{*} \mathrm{P}=0.05$; Tukey test 
tion and identification of viable cells, but this method is both labor intensive and time consuming. Nonetheless, we used the culture method to quantify E. faecalis in dental samples due to this method has shown good reproducibility when used during the various stages of treatment [16].

A $5.25 \% \mathrm{NaOCl}$ solution is routinely used for irrigation due to its efficacy in eliminating $E$. faecalis from the dentinal tubules [17]. Gomes et al. [18] have evaluated the antimicrobial action of $\mathrm{Ca}(\mathrm{OH})_{2}$, when delivered with different vehicles and against various microorganisms, including E. faecalis, and have concluded that calcium hydroxide is the best antimicrobial agent that can be used in endodontic treatments. Almyroudi et al. [19] have also confirmed the effectiveness of $\mathrm{Ca}(\mathrm{OH})_{2}$ in reducing $E$. faecalis counts from dentinal tubules after eight days of antimicrobial; however, $\mathrm{Ca}(\mathrm{OH})_{2}$, was not efficient in reducing E. faecalis counts after 14 days. Contrarily, we show that $\mathrm{Ca}(\mathrm{OH})_{2}$ treatment for 14 days resulted in either a decrease in bacterial number or their total absence. This might be explained by the fact that different vehicles were used for delivering $\mathrm{Ca}(\mathrm{OH})_{2}$; while we used glycerin as the delivery vehicle based on its ability to slowly dissociate $\mathrm{Ca}(\mathrm{OH})_{2}$, Almyroudi et al. [19] used aqueous vehicles.

Studies have shown that $E$. faecalis is able to penetrate the deep dentinal tubules, and that it is highly resistant to antimicrobial agents used in dental procedures [20]. It is important to note that the presence of Enterococcus spp. and its clinical relevance in various endodontic infectious processes as well as the high levels of resistance to antimicrobials particularly to methicillin and vancomycin are not clear.

This microorganism is capable of growing even if under conditions of nutritional scarcity and is generally considered viable but not cultivable; however, it may become cultivable under favorable conditions [16].

Chlorhexidine is the drug of choice in endodontic treatments because it has a broad antimicrobial spectrum that also includes the anaerobic bacteria associated with endodontic treatment failure. Its substantial effectiveness and low tissue toxicity further justify its use as an intracanal antimicrobial $[21,22]$. Studies have shown that even though chlorhexidine is an effective disinfectant, it is not a curative drug [22].

We evaluated the effect of chlorhexidine treatment on root canals after 7 days without any intracanal antimicrobial and found a logarithmic increase in CFU of E. faecalis; this result is in accordance with those reported previously by Delgado et al. [16]. Importantly, no recontamination was observed in the root-canal treated teeth that were not filled with any intracanal antimicrobial for seven days. This is probably because both chlorhexidine and $\mathrm{Ca}(\mathrm{OH})_{2}$ are capable of disintegrating cell membranes on physical contact, and the presence of these drugs in the root canal acts as an antimicrobial barrier.

In clinical practice, it is essential to place intracanal antimicrobial as a complementary treatment in the root canals after mechanical instrumentation. Possible failures in root canal filling help bacteria remain within the canal, thus causing failure of therapy. We therefore evaluated the residual effect of antimicrobials in removing E. faecalis and found that after seven days without drugs there as a low reduction of this microorganism. Electron microscopy revealed adequate bacterial colonization after 14 days of contamination; however, it is possible that the intracanal antimicrobials used did not sufficiently reach all areas of the canal. Similar observations have also been previously reported $[11,15]$.

A limitation of this study is that it is an in vitro study, and thus, the intraoral environment, comprising an extensive bacterial diversity, could not be reproduced. It is also possible that, in this in vitro model, sufficient nutrition owing to only a monoinfection also favored bacterial survival.

In conclusion, we report that $5.25 \%$ sodium hypochlorite, either with a $2 \%$ chlorhexidine gel or $\mathrm{Ca}(\mathrm{OH})_{2}$ is effective in reducing the number of $E$. faecalis bacteria in root canals, and that the use of chlorhexidine was more effective than $\mathrm{Ca}$ $(\mathrm{OH})_{2}$. It may be explained because chlorhexidine is adsorbed on dental surface for long time displaying a close contact with oral microorganisms. The absence of recontamination of the main canal even in the absence of intracanal antimicrobial for seven days provides further proof of their effectiveness against E. faecalis.

\section{Acknowledgments}

The authors thank Mrs. Marcia Harumi for her technical support. This study was supported by grants from CAPESPNPD (No. 2009), FAPESP (No. 2013/13652-6) and FAPES $(003 / 2010)$.

\section{References}

1) Carrotte P (2004) Endodontics: Part 2 Diagnosis and treatment planning. Brit Dent J 197: 231-238.

2) Siqueira Jr JF, Richer FNSJ, Roças IN (2006) Prospective analysis of the success of endodontic therapy index using an antimicrobial strategy / Prospective analysis of the sucess rate of endodontic therapy using an antimicrobial strategy. Rev Bras Odontol 63: 133-137.

3) Siqueira Jr JF, Lopes HP (1999) Mechanisms of antimicrobial activity of calcium hydroxide: a critical review. Int Endod J 32: 361-369.

4) Gomes BP, Ferraz CC, Vianna ME, Berber VB, Teixeira FB, et al. (2001) In vitro antibacterial activity of several concentrations of sodium hypochlorite and chlorhexidinegluconate in the elimination of Enterococcus faecalis. Int Endod J 34: 424-428.

5) Estrela C, Estrela CR, Barbin EL, Spanó JC, Marchesan MA, et al. (2002) Mechanism of action of sodium hypochlorite. Braz Dent J 13: 113-117.

6) Siqueira Jr JF, Rôças IN (2004) Polymerase chain reaction-based analysis of microorganisms associated with failed endodontic treatment. Oral Surg Oral Med Oral Pathol Oral Radiol Endod 97: 85-94.

7) Murad C, Fariniuk LF, Fidel S, Fidel RA (2008) Bacterial leakage in root canals filled with calcium hydroxide paste associated with different vehicles. Braz Dent J 19: 232-237.

8) Baumgartner JC (2004) Microbiologic aspects of endodontic infections. Can Dent Assoc J 32: 459-467.

9) Tomazinho LF, Avila-Campos MJ (2007) Detection of Porphyromonas gingivalis, Porphyromonas endodontalis, Prevotella intermedia, and Prevotella nigrescens in chronic endodontic infection. Oral Surg Oral Med Oral Pathol Oral Radiol Endod 103: 285-288.

10) Pinheiro ET, Gomes BP, Ferraz CC, Sousa EL, Teixeira FB, et al. (2003) Microorganisms from canals of root-filled teeth with periapical lesions. Int Endod J 36: 1-11. 
11) Siqueira Jr JF, Alves FR, Almeida BM, Oliveira JC, Rôças IN (2010) Ability of chemo-mechanical preparation with either rotary instruments or self-adjusting files to disinfect oval-shaped root canals. J Endod 36: 1860-1865.

12) Imura N, Otani SM, Avila-Campos MJ, Jardim EG, Zuolo ML (1997) Bacterial penetration through temporary restorative material in root-canal-treated teeth in vitro. Int Endod J 30: 381-385.

13) Roach RP, Hatton JF, Gillepsie MJ (2001) Prevention of the ingress of a known virulent bacterium into the root canal system by intracanal medicaments. J Endod 27: 657-660.

14) Williams JM, Trope M, Caplan DJ, Shugars DC (2006) Detection and quantitation of Enterococcus faecalis by real-time PCR (qPCR), reverse transcription-PCR (RT-PCR), and cultivation during endodontic treatment. J Endod 32: 715-721.

15) Gomes BP, Pinheiro ET, Gadê-Neto CR, Sousa EL, Ferraz CC, Zaia AA et al (2004) Microbiological examination of infected dental root canals, Oral Microbiol Immunol 19: 71-76.

16) Delgado RJR, Gasparoto TH, Sipert CR, Pinheiro CR, Moraes IG, Garcia RB et al (2010) Antimicrobial effects of Calcium hydroxide and chlorhexidine on Enterococcus faecalis," J Endod 36: 13891393.

17) Agrawal V, Rao MR, Dhingra K, Gopal VR, Mohapatra A, et al. (2013) An in vitro comparison of antimicrobial efficacy of three root canal irrigants-BioPure MTAD, 2\% chlorhexidinegluconate and $5.25 \%$ sodium hypochlorite as a final rinse against Enterococcus faecalis. J Contemp Dent Pract 14: 842-847.

18) Gomes BP, Ferraz CC, Vianna ME, Rosalen PL, Zaia AA, Teixeira FB et al (2002) In vitro antibacterial activity of calcium hydroxide pastes and their vehicles against selected microorganisms. Braz Dent J 13: 155-161.

19) Silveira LFM, Silveira CF, Martos J, Castro LAS (2013) Evaluation of the different irrigation regimens with sodium hypochlorite and EDTA in removing the smear layer during root canal preparation. J Micros Ultrastruct 1: 51-56.

20) Estrela C, Estrela CR, Decurcio DA, Hollanda AC, Silva JA (2007) Antimicrobial efficacy of ozonated water, gaseous ozone, sodium hypochlorite and chlorhexidine in infected human root canals. Intern Endod J 40: 83-90.

21) Piovesani JF, Semenoff-Segundo A, Pedro FLM, Borges AH, et al (2012) Antibacterial capacity of different intracanal medications on Enterococcus faecalis. Dental Press Endod 2: 53-58.

22) Ahmetoglu F, Keles A, Yalcin M, Simsek N (2014) Effectiveness of different irrigation systems on smear layer removal: A scanning electron microscopic study. Eur J Dent 8: 53-57.
Submit your manuscript to a JScholar journal and benefit from:

ศ Convenient online submission

ฯ Rigorous peer review

I Immediate publication on acceptance

- Open access: articles freely available online

9 High visibility within the field

ฯ Better discount for your subsequent articles

Submit your manuscript at http://www.jscholaronline.org/submit-manuscript.php 